\title{
Design And Implementation A System Communication Of Optical Fiber By Using Interval Wavelength (532nm-820nm) Of Diode Laser
}

\author{
Hussein TH.Khamees \\ Department of Laser and Optoelectronic Engineering, College of Engineering \Nahrain University ,Iraq
}

\begin{abstract}
The optical fiber communication system has different designs and implementations. In this work, two light sources were used in the optical system, a diode laser of a wavelength (532nm) and a light emitting diode of a wavelength $820 \mathrm{~nm}$. Multimode optical fiber is used as a channel and PIN photodiode is used as an optical detector. For each light source, the power budget for the optical design and the power-current curve have been measured by using the experimental results.
\end{abstract}

Keywords: Opticalfiber, Commnucation System, PIN,DiodeLaser,LED

\section{INTRODUCTION}

An optical communication system consists of a transmitter, which encodes a message into an optical signal, a channel, which carries the signal to its destination, and a receiver, which reproduces the message from the received optical signal.[1]

One of the most important types of optical communication system is optical Fiber communication which is based on using an optical fiber as the channel which carries the signal. A block diagram of the fiber optics communication system is shown in figure (1).[2]

Optical fiber is the most common type of channel for optical communications, however, other types of optical waveguides are used within communications gear, and have even formed the channel of very short distance (e.g. chip-to-chip, intra-chip) links in laboratory trials. The transmitters in optical fiber links are generally light-emitting diodes (LEDs) or laser diodes. Infrared light, rather than visible light is used more commonly, because optical fibers transmit infrared wavelengths with less attenuation and dispersion. The signal encoding is typically simple intensity modulation, although historically optical phase and frequency modulation have been demonstrated in the lab. The need for periodic signal regeneration was largely superseded by the introduction of the erbium-doped fiber amplifier, which extended link distances at significantly lower cost.[2]

\section{LIGTH SOURCES}

The light sources used in optical fiber communication system must have some desirable characteristics which are required for light source to function properly. The requirement which must be satisfied are [3].

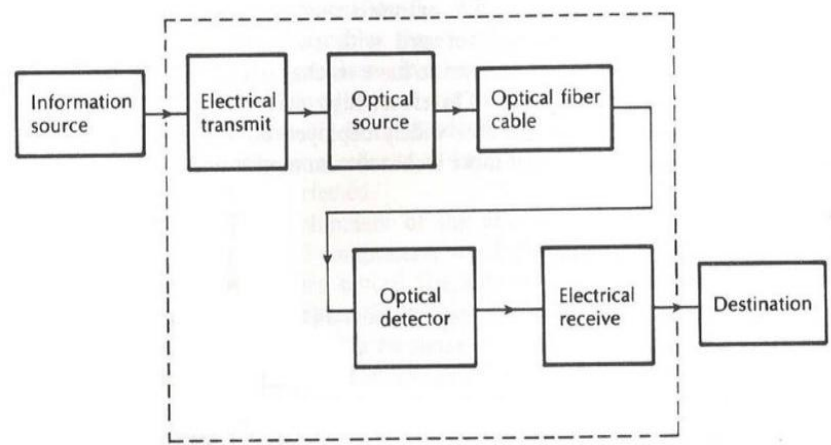

Figure (1):A block Diagram of an Optical Fiber Communication System

- Output wavelength: must coincide with the loss minima of the fiber.

- Output power: must be high, using lowest possible current and less heat.

- High output directionality: narrow spectral width.

- Wide bandwidth.

- Low distortion. 
These requirement made the LEDs and LDs the preferable light sources for optical communication system.

Table (1): Comparison of Light Sources[4]

\begin{tabular}{|l|l|}
\hline LED & \multicolumn{1}{|c|}{ LD } \\
\hline Low efficiency & High efficiency \\
\hline $\begin{array}{l}\text { Broad output } \\
\text { spectrum }\end{array}$ & $\begin{array}{l}\text { Narrow output } \\
\text { spectrum }\end{array}$ \\
\hline Incoherent beam & Coherent output beam \\
\hline Low launch power & High launch power \\
\hline $\begin{array}{l}\text { Higher distortion } \\
\text { level at the output }\end{array}$ & Less distortion \\
\hline $\begin{array}{l}\text { Suitable for shorter } \\
\text { transmission } \\
\text { distances. }\end{array}$ & $\begin{array}{l}\text { Suitable for longer } \\
\text { transmission distances }\end{array}$ \\
\hline $\begin{array}{l}\text { Simple construction } \\
\text { Construction is } \\
\text { complicated }\end{array}$ \\
\hline Longer life time & Smaller Life time \\
\hline $\begin{array}{l}\text { Lower modulation } \\
\text { bandwidth }\end{array}$ & $\begin{array}{l}\text { Higher modulation } \\
\text { bandwidth }\end{array}$ \\
\hline
\end{tabular}

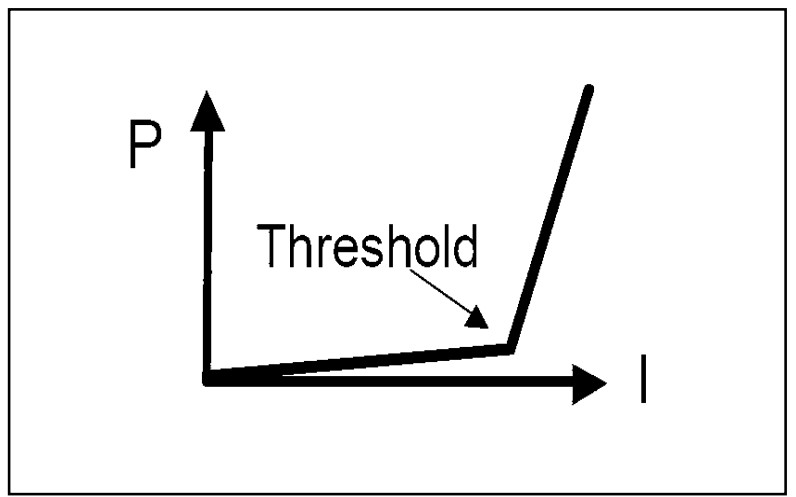

Figure (2): The radiant output power versus the injected current

III.

OPTICAL POWER AND OPTICAL POWER LINK BUDGET.

The output optical power is increased as the injection current increase but a low output power achieved below the threshold point until the current reached to the threshold where the laser action start and above the threshold a great change in the output optical power with a small change in injection current is obtained [2].

The relationship between optical output power and diode drive current is presented in figure (2) [4] .

The purpose of the optical power link budget is to ensure that enough power will reach the receiver to maintain reliable performance during the entire system lifetime, The minimum average power required by the receiver is the receiver sensitivity $\mathrm{P}_{\text {sens }}$. The average launch power $\mathrm{P}_{t}$ is generally known for any transmitter. The power budget takes an especially simple form in decibel units with optical powers expressed in $\mathrm{dBm}$ [5]. More specifically,

$\mathrm{P}_{\mathrm{t}}=\mathrm{P}_{\text {sens }}+\mathrm{C}_{\mathrm{L}}+\mathrm{M}_{\mathrm{a}}$

Where $C_{L}$ is the total channel loss and $M_{a}$ is the safety margin. If $\alpha_{f}$ is the fiber loss in decibels per kilometer, $\alpha_{\mathrm{s}}$ is the splice loss in decibels per kilometer, and $\alpha_{\mathrm{c}}$ is the connector loss in decibels then $\mathrm{C}_{\mathrm{L}}$ can be written as:

$\mathrm{C}_{\mathrm{L}}=\left(\alpha_{\mathrm{f}}+\alpha_{\mathrm{s}}\right) \mathrm{L}+\alpha_{\mathrm{c}}$

Where L: is the length of the fiber in kilometers. 


\section{EXPERIMENTAL SETUP OF OPTICAL FIBER COMMUNICATION SYSTEM.} follow:

A brief description of each of the parts of the optical fiber communication system is presented as

The optical transmitter: the optical transmitter is HFBR 1402, which contains an optical source is a LED with a wavelength of $820 \mathrm{~nm}$, and LD with wavelength of (532) $\mathrm{nm}$ which is modulated using direct intensity modulation as shown in fiqure (3). The optical receiver: the optical receiver is HFBR 2402, which contains a PIN detector and a DC amplifier as shown in figure (4).

The optical fiber is (20) $\mathrm{m}$ long with a core to cladding diameter ratio of $50 / 125 \mu \mathrm{m}$

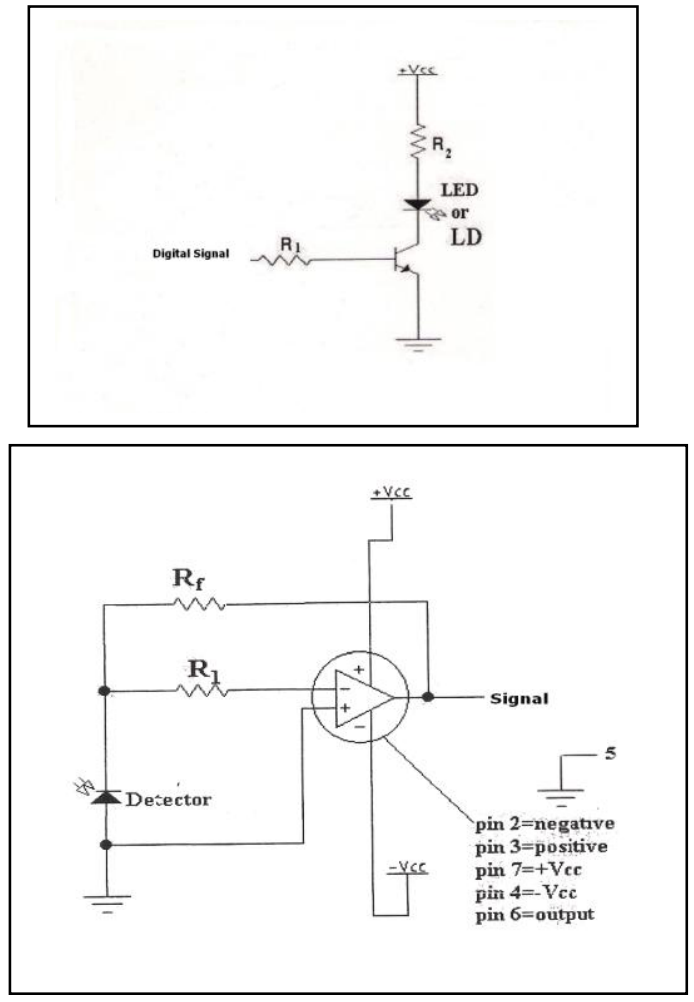

We connected the circuit as shown in figure (3). The function generator was used by passing 5 volt to the input of the transmitter circuit by using pulse waveform. In addition, the photo-diode converted the photo energy into an electric.

\section{EXPERIMENTAL RESULTS AND DISCUSSION:}

5.1 The power versus current curve for the laser diode operation:

The power-current curve was drawn depending on the values of the laser output power, which was measured using a power-meter, and the driving current, which was measured on $\mathrm{R}_{2}$, indicated in figure (5).

Figure (5) shows the P-I curve for the measured values of the power and the current for the laser diode.

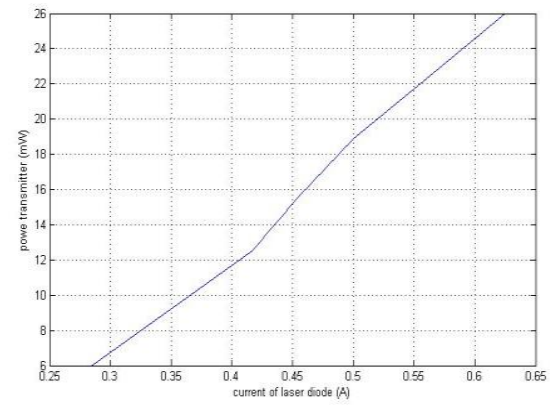

Figure (5): The power-current curve for the laser diode 
Table (2): The measured values of the power and the current for Laser

\begin{tabular}{|c|c|}
\hline Current $(\mathrm{A})$ & Power transmitter $(\mathrm{mW})$ \\
\hline 0.2846 & 6 \\
\hline 0.4167 & 12.5 \\
\hline 0.4545 & 15.6 \\
\hline 0.5000 & 18.9 \\
\hline 0.5556 & 22 \\
\hline 0.6250 & 26 \\
\hline
\end{tabular}

5.2 The power versus current curve for the light emitting diode operation:

The power-current curve was drawn depending on the values of the LED output power, which was measured using a power-meter, and the driving current, which was measured on $R_{2}$.

Figure (6) shows the P-I curve for the measured values of the power and the current for the laser diode.

Table (3) shows the measured values of the power and the current.

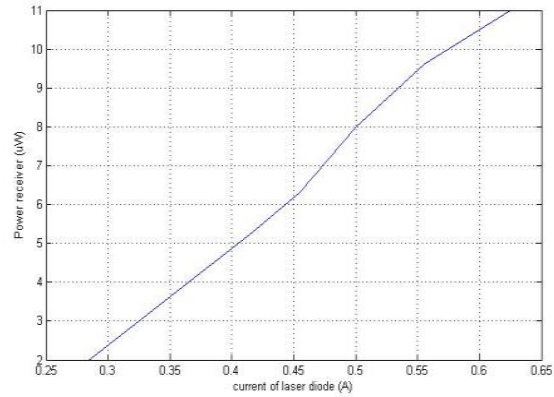

Figure (6): The power-current curve for the LED

Table (3): The measured values of the power and the current for LED

\begin{tabular}{|c|c|}
\hline Current $(\mathrm{A})$ & Power receiver $(\boldsymbol{\mu W})$ \\
\hline $\mathbf{0 . 2 8 4 6}$ & 2 \\
\hline 0.4167 & 5.3 \\
\hline 0.4545 & 6.3 \\
\hline 0.5000 & 8 \\
\hline 0.5556 & 9.6 \\
\hline 0.6250 & 11 \\
\hline
\end{tabular}

\subsection{POWER LINK BUDGET:}

The required receiver power and available transmission power, the upper limit of the allowable power loss form transmission is called the power budget specifically, if the transmission power is $\left(\mathrm{p}_{\mathrm{in}}\right)$ and the minimum required receiving power is $\left(\mathrm{P}_{\min }\right)$ the power budget.

Power budget $(\mathrm{dB})=\mathrm{P}_{\mathrm{in}}[\mathrm{dB}]-\mathrm{P}_{\min }[\mathrm{dB}]$

$\alpha=(1 / \mathrm{L}) \log \left(\mathrm{p}_{\mathrm{o}} / \mathrm{p}_{\text {in }}\right)$

where $\alpha$ is Fiber attenuation(in $\mathrm{dB} / \mathrm{Km}$ ) and $\mathrm{L}$ is a fiber length.

table (4) shows the power budget calculation of two sources LED and LD which are calculated from equations $(1),(2),(3)$ and (4). 
Table (4) the power budget calculations.

\begin{tabular}{|l|c|c|}
\hline The properties & LED & LD \\
\hline The optical power launched into & -24.55 & -15.85 \\
the fiber (in dB) & $\mathrm{dBm}$ & $\mathrm{dBm}$ \\
\hline The minimum required & -39.15 & -39.15 \\
received power(in dB) & $\mathrm{dBm}$ & $\mathrm{dBm}$ \\
\hline The total power margin (in dB) & $14.6 \mathrm{~dB}$ & $\mathbf{2 3 . 3 0} \mathrm{dB}$ \\
\hline Fiber attenuation(in $\mathrm{dB} / \mathrm{Km})$ & $3 \mathrm{~dB}$ & $\mathbf{- 0 . 1 8 6 ~ d B}$ \\
\hline The connector loss $(2 * 1.5 \mathrm{~dB})$ & $3 \mathrm{~dB}$ & $3 \mathrm{~dB}$ \\
\hline Safety margin $($ in $\mathrm{dB})$ & $6 \mathrm{~dB}$ & $\mathbf{8 d B}$ \\
\hline
\end{tabular}

\section{CONCLUTION}

Due to the use of the optical fiber as a transmission medium, the maximum distance is increased largely as compared to the distance obtained with the twisted pair cable. Because of the optical power launched into the fiber for the LD is larger than LED Then the power link budget for LD is larger than LED .The output power from the LD increases slowly with the drive current, until the threshold point, where it will increase rapidly.

The attenuation factor is increased (in case of transferring data through the air or fiber) when the distance between the transmitter and the receiver is increased with the decreasing of the received power.

\section{REFERENCES}

Books:

1. Agrawal, Govind P. Fiber-Optic Communication Systems. New York: John Wiley \& Sons. Isbn 0-471-21571-6) (2002).

2. John M. Senior, 'Optical Fiber Communications Principles And Practice', Second Edition, Prentice Hall International, 1992.

3. Govind P. Agrawal, "Lightwave Technology Telecommunication Systems", John Wiley \& Sons Inc., 2005.

Thesis:

4. Z. Ghassemlooy, "Optical Fiber Communication Systems Lecture Notes", Electronics \& It Division School of Engineering, Sheffield Hallam University U.K.

5. Stefan Nilsson-Gistvik, "Optical Fiber Theory for Communication Networks", Second Edition, Ericsson Network Technologies AB Hudiksvall Sweden, 2002. 